\title{
Como vai a Educação Gerontológica nas Escolas Públicas do Distrito Federal? Um estudo com idosos e jovens
}

\section{HowistheGerontologica Edrcationgaing in PudicSthools of theFederd Distrid? Astudy with eddelyandjuveriles}

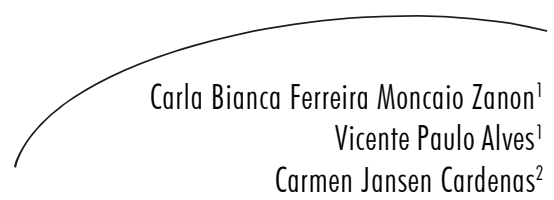

O presente artigo é fruto de uma pesquisa de campo quali-quantitativa que embasou uma dissertação de mestrado. A pesquisa buscou conhecer a opinião de alunos de escolas públicas do Ensino Fundamental e Médio do Distrito Federal (DF) e de idosos da mesma comunidade a respeito do envelhecimento e sua correlação com a existência ou não de preconceitos. Buscamos averiguar se um grupo de escolas desenvolve algumas ações voltadas à formação de hábitos, valores e atitudes direcionadas à superação de preconceitos e à aproximação entre as gerações (intergeracionalidade). Os dados foram coletados por meio de três instrumentos: 1) aplicação de um questionário sócio-demográfico e da Escala para Avaliação de Atitudes em Relação ao Idoso validada por Neri; 2) avaliação de oito propostas pedagógicas de escolas públicas do Ensino Fundamental e Médio do DF, que nos permitiram conhecer a dinâmica do contexto pesquisado; e 3) realização de 18 entrevistas, sendo cinco com jovens das escolas, oito com diretores (cujas propostas pedagógicas foram analisadas), e cinco com idosos (residentes na área central de Brasília). Diante dos resultados do presente estudo, podemos afirmar que predominaram atitudes mais positivas do que negativas em ambos os grupos. Não obstante, ao confrontá-los com as entrevistas, percebemos que os entrevistados responderam a questões similares às apresentadas na Escala Neri de forma mais negativa. Inferimos que este fato se deva à existência de preconceito implícito em relação ao idoso e à velhice. Outra constatação importante é a inexistência de atividades voltadas aos idosos, e/ou a aproximação destes com outras gerações nas escolas pesquisadas. Os dados obtidos com esta pesquisa sugerem que a educação gerontológica deve fazer parte do currículo escolar, visando a aproximar gerações e superar possíveis preconceitos, possibilitando a troca de experiências e a melhoria da qualidade de vida de todos.

\footnotetext{
Programa de Pós-Graduação em Gerontologia. Universidade Católica de Brasília. Brasília, DF,
Brasil.

Programa de Pós-Graduação em Gerontologia. Universidade Católica de Brasília. Brasília, DF,
Brasil.

2 Programas de Pós-Graduação em Psicologia e em Gerontologia. Universidade Católica de Brasília. Brasília, DF, Brasil.
}

Correspondência / Correspondence

Carla Bianca Ferreira Moncaio Zanon

E-mail: carlazanon@hotmail.com

\author{
Palavras-chave: \\ Envelhecimento. \\ Educação. Geriatria, \\ Qualidade de vida, Ensino \\ Fundamental e \\ médio.Encontros \\ intergeracionais. Atitudes.
}




\section{Abstract}

This paper results from quali-quantitative field research that supports a master's dissertation. The research sought to know the opinion of 58 students from elementary and high public schools in the Federal District and 54 elderly of the community about aging, old age and old people and its correlation with the presence or not of prejudice. We sought to determine if a group of eight schools develops some actions aimed to form habits, values and attitudes to overcome prejudices and end the generation gap (inter-generationality). The research data were collected through three instruments: 1) the application of a sociodemographic questionnaire and the Scale for the Assessment of Attitudes Toward the Elderly validated by Neri; 2) analyze of eight Pedagogical Projects of elementary and high schools of the Federal District, which allowed us to understand the dynamics of the context studied; and 3) completion of eighteen interviews, five with juvenile from schools, eight with directors (whose pedagogical proposals were examined) and five with elderly (residents in the central area of Brasilia).From the results of this study, it was possible to argue that prevailed more positive than negative attitudes in both groups. However, when they were submitted to the interviews, it has been noticed that the interviewees answered similar questions at the scale Neri and at Inventory Sheppard in a more negative way. We imply that it's due to the existence of implicit prejudice against the elderly and old age revealed through the interviews. Another important finding is the lack of activities geared to the elderly, and/or approach of them with other generations in schools surveyed. Our data suggest that gerontology education should be part of the school curriculum, aiming to approach generations in order to overcome potential prejudices, making possible the exchange of experiences and the improvement of life quality for all.
Key words: Aging.

Education. Geriatrics.

Quality of life. Education.

Primary and Secondary.

Meetings

intergenerational.

Attitudes.

\section{INTRODUÇ̃̃OO}

$\mathrm{Na}$ atualidade, os pesquisadores do envelhecimento, como Neri, ${ }^{1}$ Cachioni, ${ }^{2}$ Camarano, ${ }^{3}$ Faleiros e Rebouças ${ }^{4}$ e Todaro ${ }^{5}$ têm realizado estudos relacionados ao envelhecimento. Eles tentaram perceber as necessidades e problemas decorrentes das mudanças biopsicossociais da velhice de forma a amenizá-la e até mesmo superálas. Um dos problemas detectados é a existência de preconceitos e estereótipos relacionados à velhice, que precisam ser superados. Ao analisar essa situação, nos dispusemos a investigar a percepção de 58 alunos de escolas públicas do Ensino Fundamental e Médio e 54 idosos da comunidade do DF a respeito do envelhecimento, visando a detectar a existência ou não de preconceitos e estereótipos nessa amostra.

Nas últimas décadas, o aumento da população idosa, o decréscimo das taxas de natalidade e os avanços das ciências são apontados por Camarano ${ }^{3}$ Faleiros e Rebouças ${ }^{4}$ como fatores impactantes dessa longevidade. A expectativa para o ano 2025 no Brasil é de um contingente de, aproximadamente, 32 milhões de idosos, fazendo com que o país ocupe o sexto lugar no mundo em população idosa (IBGE').

A Política Nacional do Idoso, ${ }^{7}$ o Estatuto do Idoso $^{8} \mathrm{e}$ as disposições decorrentes desses documentos indicam e enfatizam a importância de cuidados, tais como prevenção, promoção da educação e a aproximação entre os jovens e idosos (intergeracionalidade).

A presente pesquisa nasceu da preocupação com a responsabilidade da educação em cumprir seu papel social na contribuição da construção do conhecimento simultaneamente às de atitudes e valores que venham a tornar os estudantes cidadãos solidários, críticos e participativos, 
propiciando um espaço de convivência social que favoreça a inclusão de todas as pessoas. Veremos que o método utilizado nos possibilitou chegar a resultados semelhantes àqueles presentes nas atuais discussões da área gerontológica, abrindo novas perspectivas para que nas instituições escolares possam circular representações sociais, ideias, sentimentos e atitudes formativas que se contraponham àquelas circundantes na sociedade. Numa sociedade muitas vezes individualista, violenta e excludente, ser diferente pode ser sinônimo de exclusão e o ter ainda se sobrepõe ao ser. Podem nos iluminar as reflexões de Jacques Delors, ${ }^{9}$ ao afirmar que "aprender a viver juntos" representa hoje em dia um dos maiores desafios da educação e que ela sozinha não é capaz de modificar essa situação real.

O estudo objetivou investigar a percepção de 58 alunos de escolas do Ensino Fundamental e Médio e 54 idosos da comunidade do Distrito Federal (DF) a respeito do envelhecimento, bem como verificar que ações são desenvolvidas em oito escolas, no sentido de favorecer a formação de valores, hábitos e atitudes entre as gerações. Assim, foi possível contribuir para a construção de políticas públicas educacionais que pudessem envolver a juventude e o idoso, buscando a integração intergeracional entre eles.

\section{MÉTODO}

Esta pesquisa foi de natureza quantiqualitativa, o que segundo Lüdke \& André, ${ }^{10}$ é capaz de promover o confronto entre os dados, as evidências, as informações coletadas sobre determinado assunto e o conhecimento teórico acumulado a respeito dele. Os dados foram coletados com instrumentos distintos, a saber: questionário sócio-demográfico, Escala Diferencial Semântica de Atitudes (Escala Neri), ${ }^{11}$ entrevistas semiestruturadas e análise documental das oito escolas pesquisadas.
A investigação abrangeu 112 sujeitos, sendo 54 maiores de 60 anos e 58 jovens entre 13 e 24 anos, todos residentes no Distrito Federal (DF). Para efeito de compreensão, comparamos os dois grupos sob critério de idade: o Grupo 1, formado por idosos residentes na área central de Brasília; e o Grupo 2, jovens estudantes das escolas do Ensino Fundamental e Médio do DF da mesma localidade. Todos os participantes assinaram o termo de consentimento livre e esclarecido, conforme as exigências do Comitê de Ética em Pesquisa (aprovado pela Universidade Católica de Brasília, em 17 de fevereiro de 2009, sob registro $\mathrm{n}^{\circ}$ CEP/UCB 04/2009).

Por meio do questionário sócio-demográfico, levantamos dados relativos a gênero, idade, escolaridade e renda familiar aproximada. A Escala para Avaliação de Atitudes em Relação ao Idoso (Escala Neri) ${ }^{11}$ é uma escala diferencial semântica cujos itens são representados por dois adjetivos em oposição. Mede a intensidade das respostas, que é expressa numa variação de cinco pontos pela posição relativa dos adjetivos positivos ou negativos em cada par. Esta ferramenta contém 30 pares de adjetivos relacionados a quatro domínios fatoriais: 1$)$ Cognitivo; 2) Agência; 3) Relacionamento Social; 4) Persona. O domínio “Cognitivo" é relativo à capacidade de processamento da informação e de solução de problemas, com reflexos sobre a adaptação social, sendo composto de dez itens; o domínio "Agência" reflete a autonomia e instrumentalidade para a realização de tarefas e é composto de cinco itens; o domínio "Relacionamento Social" cobre aspectos afetivomotivacionais e sua influência na interação social dos idosos, composto por sete itens. Por fim, o domínio "Persona" alude à imagem social, refletindo os rótulos sociais comumente usados para designar e discriminar os idosos, com sete itens. A escala segue o formato da escala Likert". Os dados dos dois instrumentos foram lançados e tabulados no programa estatístico SPSS (Statistical Package for Social Sciences), versão 17.0 para Windows.

A adoção da escala Likert, se deve ao método de atitude proposto por Rensis Likert, por ser mais preciso, onde o entrevistado, ao responder o questionário, tem a liberdade para posicionar-se em relação a cada item numa escala de cinco pontos. Segundo Selltiz, C. et al Métodos de pesquisa das relações sociais. São Paulo: Herder, (1965), a escala tipo Likert é a escala somatória mais frequentemente utilizada no estudo de atitudes sociais. A Escala Likert é um tipo de escala de resposta psicométrica, representa um avanço em relação às dicotômicas, pois não forçam a resposta dos sujeitos para dois pontos exclusivos. Ao responderem a um questionário baseado nesta escala, os entrevistados especificam seu nível de concordância com uma afirmação. 
As entrevistas representam um dos intrumentos básicos da coleta de dados, sendo uma das principais técnicas de trabalho utilizada em pesquisas sociais, segundo Lüdke \& André ${ }^{10}$ Entrevistamos os idosos em suas residências, para diminuir os transtornos dos deslocamentos; já com os jovens, as entrevistas foram realizadas nas próprias escolas onde, na oportunidade, entrevistamos os diretores. Todas as entrevistas tiveram a duração média de 60 minutos, seguindo um roteiro previamente estabelecido (que está no final desse artigo). As entrevistas foram gravadas e depois transcritas, sendo que alguns trechos aparecem ao longo da "discussão".

As entrevistas permitiram a correção, esclarecimentos e adaptações que as tornaram sobremaneira eficaz na obtenção das informações desejadas. Elas permitiram aprofundar as questões abordadas no questionário e na escala. Os participantes das entrevistas foram escolhidos aleatoriamente mediante a disponibilidade de tempo em participar da mesma. Mantivemos o mesmo número de jovens e idosos, ou seja, cinco para cinco, para manter o equilíbrio entre os grupos.

Com relação à análise documental das propostas pedagógicas (PP), procuramos nas escolas públicas do $\mathrm{DF}$ aquelas que desenvolviam projetos alusivos à formação de valores. Dessas escolas escolhemos oito, para avaliação de ideias que pudessem ser identificadas como tentativas de educação gerontológica e de intergeracionalidade.

\section{RESULTADOS}

\section{Questionário sócio-demográfico}

Do total de 112 participantes, $58,7 \%$ eram do sexo feminino $41,3 \%$ sexo masculino. Asidades dos jovens $(52,3 \%)$ variaram entre 13 a 24 anos e a dos idosos $(47,6 \%)$ de 60 anos a mais (conforme figura 1$)$.

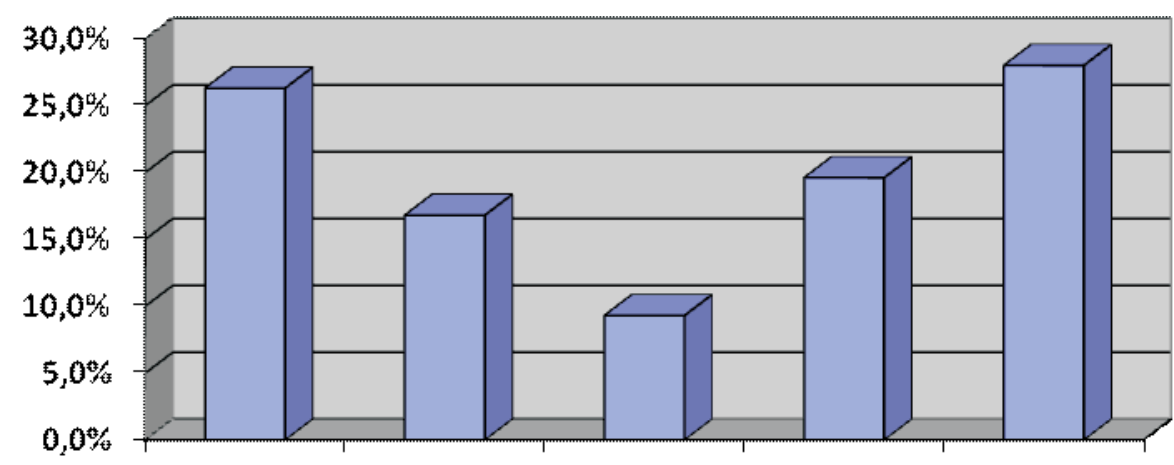

13 a 15 anos 16 a 18 anos 19 a 24 anos 60 a 64 anos Acima de 65 anos

Figura 1 - Faixa Etária de Jovens e Idosos. Brasília, DF, 2009.

Em relação à escolaridade, os dados indicaram: ensino fundamental - $47 \%$; ensino médio - $28,8 \%$ e $24 \%$ do ensino superior. A renda familiar aproximada ficou entre $\mathrm{R} \$ 500,00$ e $\mathrm{R} \$ 2000,00$ $(57,8 \%)$, de $R \$ 2.001,00$ a $R \$ 3.000$ (9,8\%) e acima de $R \$ 3.001,00(32,4 \%)$.
A maioria dos participantes não mora com pessoas idosas $(74,1 \%)$; moram com os avós $(10,2 \%)$; com os pais $(1,9 \%)$; e com o esposo (a) $(13,9 \%)$. 
Escala Diferencial Semântica de Atitudes em Relação à Velhice (Escala Neri)

Por meio da aplicação da Escala Neri, avaliamos as atitudes dos dois grupos pesquisados em relação à velhice: o Grupo 1, formado por idosos residentes na área central de Brasília, que ao responderem ao questionário, aceitaram participar das entrevistas; e o Grupo 2 (jovens estudantes das escolas do Ensino Fundamental e Médio do DF, contatados da mesma forma). Eles foram agrupados de acordo com as sequências de domínios fatoriais desta escala. A gradação de respostas de cinco itens foi reduzida a três (positiva, negativa e neutra) com a finalidade de simplificar a apresentação dos dados.

Tabela 1 - Atitudes da Escala Neri ${ }^{11}$ de jovens e idosos. Brasília, DF, 2009.

\begin{tabular}{llll}
\hline Atitudes & Jovens & Idosos & Total \\
\hline Positivas & $49,3 \%$ & $46,7 \%$ & $48,1 \%$ \\
Neutras & $23,6 \%$ & $25,9 \%$ & $24,6 \%$ \\
Negativas & $27,1 \%$ & $27,4 \%$ & $27,3 \%$ \\
\hline Total & $100,0 \%$ & $100,0 \%$ & $100,0 \%$ \\
\hline
\end{tabular}

Nos itens do domínio "Cognição", encontramos algumas semelhanças de atitudes (respostas) positivas entre idosos e jovens, respectivamente, nos itens da categoria "Cognição": sábio (92,5\% e 98,2\%); preciso (82\% e 75,9\%); concentrado (62\% e 65,5\%); persistente $(59,6 \%$ e $51,8 \%)$; alerta $(53,8 \%$ e $55,4 \%)$. Foram apuradas semelhanças de respostas negativas referentes à lentidão (53,8\% e 49\%). Os idosos discordaram dos jovens nos itens "inseguro", "rígido", pois se consideram mais inseguros $(54,9 \%$, e $35,2 \%)$ e mais rígidos $(62,5 \%$ e 47,6$)$ do que são percebidos pelos jovens.

O domínio "Agência" reflete a autonomia e instrumentalidade para a realização de tarefas. Os itens "entusiasmado" (92,6\% e 94,8\%); "esperançoso" (58,5\% e $63,2 \%)$ e "produtivo" $(47,1 \%$ e $47,3 \%)$ foram avaliados positivamente por idosos e jovens, respectivamente. Algumas semelhanças de atitudes foram avaliadas negativamente por ambos, referentes à "passividade" (36,5\% e 30,4\%). Os jovens percebem o idoso mais "independente" (44\%) do que os idosos em relação a eles próprios $(35,8 \%)$.
Apenas $34 \%$ idosos e $37 \%$ jovens consideram o idoso "saudável".

No domínio "Relacionamento Social”, foram encontradas algumas semelhanças de atitudes (respostas) positivas entre idosos e jovens, respectivamente. "Bem-humorado" $(82,7 \%$ e $63,2 \%)$; "cordial" (60,4\% e $55,8 \%$ ) e confiantes $(73,6 \%$ e $64,9 \%)$, sendo que os idosos se perceberem mais bem-humorados, cordiais e confiantes do que são reconhecidos pelos jovens. Os itens que obtiveram avaliação mais negativa por ambos os grupos foram "desinteressados" (74\% e 48,2\%) e "mesquinhos" (59,2\% e 63,7\%).

No domínio "Persona", os adjetivos com avaliação mais positiva feita pelos idosos e jovens foram “aceito" (64,7\% e 62,5\%) e "agradável” (62,3\% e 70,9\%). Tanto os idosos quanto os jovens percebem o idoso mais "introvertido" (53,2\% e 48,2\%); em contrapartida, ambos veem o idoso mais "valorizado" (45,3\% e $50 \%)$. O adjetivo "progressista" foi avaliado de forma mais neutra pelos idosos $(33,8 \%)$ e positiva para os jovens $(55,6 \%)$. Os jovens percebem o idoso mais "atualizado" (40\%) do que os idosos se sentem $(25,5 \%)$. 
Análise documental

Nas oito propostas pedagógicas analisadas, não encontramos nenhum projeto que fizesse referência direta ao idoso ou à intergeracionalidade. Encontramos três projetos sobre valores e um sobre cidadania, cujos conteúdos desenvolvidos se aproximaram do nosso tema, pois falam da paz, amor, respeito, solidariedade responsabilidade, diversidade cultural, amizade, solidariedade, família e cooperação.

\section{DISCUSSÃO}

A análise das respostas expressas por meio da Escala Néri e das entrevistas corroboraram as propostas teóricas da gerontologia, como ciência multidisciplinar, de acordo com Baltes ${ }^{12}$ e Néri, ${ }^{13}$ no que se refere à multidimensionalidade das atitudes e significados a respeito do envelhecimento.

As atitudes são definidas como avaliações de indivíduos e grupos em relação a objetos sociais, para as quais concorrem processos afetivos e cognitivos. ${ }^{14}$ Elas estão relacionadas a comportamentos, valores preditivos daquilo que a pessoa diz em relação ao que faz. As atitudes relacionadas à velhice são aprendidas ao longo da vida, a partir da convivência com idosos ou com nosso próprio envelhecimento.

A literatura sobre atitudes em relação à velhice é bem contraditória; no entanto, os dados empíricos mostram que, nas sociedades ocidentais, elas são predominantemente negativas. ${ }^{1}$ Reconhecemos que o envelhecimento é um processo complexo multidimensional e heterogêneo, compreendendo uma relação biopsicossocial-cultural, como ficou demonstrado pelas visões plurais e multidimensionais dos participantes da pesquisa. Os resultados revelaram que os participantes têm predisposição em geral mais positivas do que negativas frente a esse objeto.

Os resultados gerais da aplicação da Escala Neri, sobre as atitudes dos jovens e dos idosos em relação aos idosos, foram mais positivos $(48,1 \%)$, moderadamente negativos $(27,3 \%)$ e neutros $(24,6 \%)$. Dados semelhantes foram encontrados por Neri (1991) em sua pesquisa. Outro achado semelhante ao do dela foi que a amostra não revelou correlação entre os itens avaliados e a idade dos sujeitos. Por meio do teste qui-quadrado, cujo número é 5,576 e o valor 0,062 é o p-valor do teste, concluímos que as frequências observadas não são diferentes das esperadas portanto, não há associação entre as atitudes (positivas, negativas e neutras) e a idade (jovens e idosos). Ficou evidente que os indivíduos jovens e idosos reagem da mesma maneira sobre as questões da Escala Neri, ou seja, são semelhantes às opiniões manifestadas pelos idosos e pelos jovens a respeito da velhice.

Podemos atribuir ao preconceito implícito, percebido por meio das entrevistas realizadas, uma das causas das avaliações sobre as atitudes serem mais positivas do que negativas. Levy ${ }^{15}$ nos alerta para a existência desse tipo de preconceito, que desperta em nós pensamentos, sentimentos e comportamentos que passam a operar sem nosso conhecimento ou mesmo sob controle consciente. Para tanto, o autor, juntamente com seus colaboradores, têm tentado descobrir as múltiplas formas em que esse tipo de preconceito se infiltra em nossos pensamentos e comportamentos. Segundo o autor, uma das formas para erradicar o preconceito é tomar consciência dos diferentes tipos existentes, seja ele explícito ou implícito. Acreditamos que por meio da educação das pessoas de diferentes gerações e também da aproximação entre elas, o envelhecimento poderá ser mais compreendido e vivido, e todos poderão conviver de forma mais harmônica.

A categoria "Cognição" é relativa à capacidade de processamento da informação e de solução de problemas com reflexos sobre a adaptação social. Não obstante terem sido encontradas respostas mais positivas entre idosos e jovens nessa categoria, contraditoriamente, ao confrontá-las com as entrevistas, percebemos que os entrevistados responderam a questões similares de forma mais negativa. Os jovens acreditam que os idosos demonstram ter alguma dificuldade para lidar com 
as novas tecnologias, sendo mais lentos, em relação a eles, para processar novos conhecimentos e também para solucionar problemas. Vejam os depoimentos:

PESQUISADORA: Computador, televisão, caixa eletrônico, celular, você acha que para o idoso é difícil mexer com tudo isso?

RESPOSTA: Para alguns não, mas para algunsé um sacrifício mexer naquilo ali (W, 14 anos).

RESPOSTA: É difícil... sei lá, esse é um mundo novo pra eles, não sei, um mundo novo... Alguns se interessam, mas tem alguns que não se interessam, acho normale não se interessam por isso (L, 17anos).

RESPOSTA: Convivem com dificuldades. Porque no tempo deles não existia isso, né? E quando eles ficaram mais velhos é que veio existir. E a pessoa velha já é mais difícil para aprender as coisas (J, 14 anos).

RESPOSTA: Não tenho medo não. Sabe, eu vou, não diria nem com entusiasmo, com confiança em mim. Tenho confianca no que eu faço, eu falho, eu erro como todas as pessoas, mas eu procuro dar o melhor de mim (C, 71 anos).

Alguns idosos também assumiram ter certa dificuldade com as novas tecnologias e outros não. Sabe-se que, na atualidade, a inclusão social está relacionada também com a inclusão digital, e nesse campo há muito o que realizar, como ficou demonstado na pesquisa do SESC/Perseu Abramo, ${ }^{16}$ que mostrou que somente $10 \%$ dos idosos afirmam usar o computador e apenas $4 \%$ utilizam a internet.

Uma vez que um dos objetivos deste trabalho foi conhecer opiniões e estereótipos relativos à velhice com vistas à aproximação entre as gerações, vislumbramos nesta situação possibilidades contrutivas que viriam a favorecer trocas intergeracionais, onde idosos e jovens poderiam colaborar uns com os outros. $\mathrm{Na}$ esteira desta reflexão sobre a possibilidade de trocas intergeracionais, Ferrigno ${ }^{17}$ apresenta o novo programa, chamado Internet Livre, promovido pelo SESC-SP. Os jovens monitores orientam os idosos a manejarem o computador e a navegarem pela internet. Os idosos ficam felizes pelas novas descobertas e os jovens, satisfeitos por poderem colaborar.

Outras atitudes avaliadas negativamente por ambos os grupos, que demonstram relacionar à velhice apenas à perda, encontrados neste e em outros trabalhos, como os de Neri, ${ }^{1}$ Andrade, ${ }^{18}$ SESC/Perseu Abramo, ${ }^{16}$ foram atividade, produtividade, saúde e independência. Os idosos, em geral, são considerados mais "passivos" do que “ativos," somente $36,5 \%$ deles e $30,4 \%$ dos jovens consideraram positivamente a atividade. Nesta direção, a Organização Mundial de Saúde ${ }^{19}$ define atividade como "a participação contínua nas questões sociais, econômicas, culturais, espirituais e civis, e não somente a capacidade de estar fisicamente ativo ou de fazer parte da força de trabalho". Esta foi uma das questões apresentadas aos entrevistados com objetivo de elucidar qual o significado de atividade para eles. A maioria dos jovens respondeu conforme o senso comum, entendendo como sendo atividade física. Contudo, os idosos demonstraram apreender o sentido mais próximo do definido pela OMS, e se declararam pessoas ativas, como nos relatos:

Eu gosto de escrever, você viu umas trovas lá na casa da Pia que eu escrevi não?... Eu gosto muito de conversar, principalmente com pessoas jovens como você, en gosto. Gosto de fazer as coisas de casa, inércia não écomigo não. Gosto de mexer com as plantas... Gosto de fazer minhas caminhadas de manhã, saio todo diaspela manhã 40 minutos (D, 86 anos).

Os idosos se percebem mais “independentes" (44\%) do que são avaliados pelos jovens (35,8\%). Apenas 34\% idosos e $37 \%$ jovens consideram o idoso "saudável". As doenças e as debilidades físicas são para a maioria dos sujeitos da pesquisa o principal sinal de que a velhice já chegou. Não obstante, declaram que não se sentem velhos: $34 \%$ dos idosos responderam que a velhice é um estado de espírito. Resultados semelhantes também refletem os achados do SESC/Perseu Abramo, ${ }^{16}$ segundo o qual os idosos brasileiros responderam que só a partir dos 70 anos sentem-se como tal.

É importante destacar que os jovens valorizam a capacidade de adaptação dos idosos. Em certos 
casos, como os citados no trabalho de Andrade, ${ }^{18}$ não se tratava de um ganho, mas de uma perda de capacidade, pois não era adaptação, era resignação ou mesmo total falta de escolha de alguns idosos asilados.

Complementando essas reflexões, concordamos com a teoria de ciclo vital desenvolvida por Erikson, ${ }^{20}$ na qual a adaptação estava relacionada a ganhos. Os idosos citados por Erikson consideravam-se mais adaptados ao meio - em decorrência, mais tolerantes, pacientes, abertos e mais compreensivos do que quando mais jovens. Neste sentido, alguns estudos levantados por Sommerhalder \& Nogueira ${ }^{21}$ mostram que, em geral, os idosos mantêm a visão positiva de si mesmos e a capacidade para controlar suas próprias vidas de forma eficaz, e ainda que alguns indivíduos são capazes de ajustar seus projetos de vida, de acordo com as condições atuais.

No domínio "Cognição", o adjetivo positivo com maior percentual foi "sábio", representando $92,5 \%$ e $98,2 \%$ das respostas dos idosos e dos jovens, respectivamente. Nas pesquisas "Idosos no Brasil" SESC/Perseu Abramo, ${ }^{16}$ na de Neri, ${ }^{1}$ e também na de Cachioni, ${ }^{2}$ a sabedoria também foi citada como referência positiva em relação aos idosos. Não obstante, Neri ${ }^{1}$ chama a atenção para o fato de a sabedoria não estar atrelada à criatividade ou geratividade, mas sim ao sentido de "memória, quantidade e qualidade de experiência vivida e da possibilidade de recorrência ao passado para a resolução de problemas atuais".

Em um mundo onde as mudanças tecnológicas e sociais acontecem de forma rápida, onde tudo poderia ser armazenado em chip de computador, a referida autora considera eufemismo considerar o idoso sábio, e indaga quando e efetivamente por quem ele é ouvido. Talvez por isso se espere que ele seja atualizado e progressista, para não estorvar a produtividade dos mais jovens.

No domínio "Relacionamento Social", foram encontradas algumas semelhanças de atitudes (respostas) positivas entre idosos e jovens, como "bem-humorado" (82,7\% e 63,2\%); "cordial"
$(60,4 \%$ e $55,8 \%)$ e confiantes $(73,6 \%$ e $64,9 \%)$, sendo que os idosos se perceberem mais bemhumorados, cordiais e confiantes do que são reconhecidos pelos jovens. Esse fato foi confirmado nas entrevistas, onde os jovens definiram alguns idosos como sendo pessoas "chatas", "rabugentas", “implicantes". Ao serem questionados se a situação mudou quando houve possibilidade de conhecer melhor aquela pessoa, alguns demonstram ter mudado de opinião. Conforme relato:

Eu não tinha muita convivência com pessoa idosa, en achava, por exemplo, que a minha vizinha era xarope, chata, quando a gente ia jogar bola na frente da casa dela, ficava implicando. Mas, depois que eu viajei aí eu conbeci meu pai e conbeci minha avó também. Depois que eu conbeci ela melhor eu descobri que os idosos podem ser chatos, mas às vezes são muito legais. Tipo assim, depois que a gente conbece o idoso, tem mais paciência com eles (W, 14 anos).

Acreditamos que a aproximação entre as gerações poderá fomentar relacionamentos mais favoráveis para todos, colaborando ainda para a minimização ou quem sabe até a superação de preconceitos relacionados à velhice e ao velho. Nos estudos de Souza, ${ }^{22}$ Andrade ${ }^{18}$ e Novaes, ${ }^{23}$ dados semelhantes foram encontrados. Por meio do diálogo interativo, da abertura para o outro, da compreensão e da aceitação mútuas, do senso de humor e, ainda, da renovação de espaços de convivência, a vida possa ser prazerosa e rica, envolvendo todas as idades.

O domínio "Persona" acena para a imagem social, refletindo os rótulos sociais comumente usados para designar e discriminar os gerontes. Nesta categoria, o adjetivo com avaliação mais positiva, tanto para idosos como para jovens, respectivamente, foi "aceito" (64,7\% e 62,5\%) e "agradável" (62,3\% e 70,9\%). Ambos percebem que o idoso é "introvertido" (53,2\% e 48,2\%) e veem o idoso mais "valorizado" (45,3\% e 50\%). Além disso, os jovens acharam os idosos mais "atualizados" (40\%) do que os idosos se sentem $(25,5 \%)$, não obstante afirmarem nas entrevistas que eles são desatualizados. 
Como vimos anteriormente, as atitudes das pessoas para com os idosos podem ser explícitas ou implícitas, ou seja, disponíveis ou não para a experiência consciente. As atitudes implícitas têm forte influência sobre o comportamento, gerando às vezes comportamentos incoerentes, segundo Neri. ${ }^{14}$ Tal fato foi confirmado nesta pesquisa, uma vez que os dados obtidos revelaram predisposição em geral mais positivas do que negativas frente ao geronte, não obstante $64 \%$ dos idosos e $62,5 \%$ dos jovens assumirem que os velhos são rejeitados. Mas rejeitados por quem? Poucos admitem que rejeitam o velho, e talvez o façam de forma inconsciente e/ou implícita.

$\mathrm{Na}$ esteira desta reflexão, Alves ${ }^{24}$ esclarece que um dos piores inimigos da velhice é a perda do respeito social. A pessoa desvalorizada considerase um "peso" para a família e para a sociedade, por não ter mais a mesma capacidade de trabalho de uma pessoa jovem. Infelizmente, com frequência, as pessoas são consideradas idosas diante da sociedade no momento em que enceram suas atividades produtivas ou aposentam-se. Os idosos (45\%) se declararam menos valorizados do que são percebidos pelos jovens (50\%). Os idosos mais valorizados pelos jovens entrevistados são os que aparentam mais juventude, vigor físico e disposição.

Motta $^{25}$ aponta que a classificação de pessoas em termo de juventude e velhice não está relacionada apenas ao tempo vivido ou ao estado de conservação do corpo e da mente, mas sobretudo ao tipo de relação estabelecida entre as gerações e entre as classes sociais. Infere-se que os jovens entrevistados também foram influenciados pela ideia de envelhecimento ideal, bem-sucedido, de uma longa velhice, sem perda do vigor físico e da agilidade mental, fato este que atrai o interesse das pessoas desde a Antiguidade, como informaram Sommerhalder \& Nogueira. ${ }^{21}$

A respeito da relação entre as gerações, em que algumas pessoas consideram os idosos desmemoriados, confusos ou “caducos", expressão que apareceu em algumas entrevistas, é relevante apresentar o depoimento da Sra. W, 84 anos:
Eu tenho a impressão de que as pessoas não acreditam muito no idoso, né? Por exemplo, se eu dou uma informação,... uma bobagem, exemplo, outro dia estavam falando do tal de Popó Bueno e Cacá Bueno, filhos do Galvão Bueno que correm, eu disse são dois, tem o Popó e o Cacá. Que nada mamãe você ta confusa, o Popó é o lutador de Box. Eu disse, não, tenho certeza de que são dois, eu nem me interesso por isso não, mas eu vejo televisão, leio jornal,... Mas uns dias depois apareceu uma lista no Correio Brasiliense... Popó Bueno. Eu falei viu?

Segundo Andrade ${ }^{18}$ e Novaes, ${ }^{23}$ é comum familiares optarem por viver separados dos idosos, dada a sua necessidade de autonomia, que não permite disponibilidade de tempo para cuidado, amparo e segurança deles. A troca intergeracional, por sua vez, poderia neutralizar a tendência de afastamento dos idosos dos contextos sociais e familiares. Assim, vislumbramos o envolvimento das diferentes gerações em programas socioeducativos nas suas diferentes configurações do habitat social para todas as gerações, evitando a segregação e a formação de guetos, aproveitando espaços interativos disponíveis nas escolas, parques, centros de saúde, centros culturais, condomínios, dentre outros espaços que couberem em nossa imaginação.

\section{CONCLUSÃO}

Ao investigar a atitude a respeito do envelhecimento, presente em alunos de um grupo de escolas do Ensino Fundamental e Médio e nos idosos da comunidade do DF, participantes da pesquisa, podemos vislumbrar os grandes desafios que esse tipo de pesquisa oferece. Sobretudo se pensarmos que as propostas pedagógicas das escolas no Distrito Federal pesquisadas ainda não contemplam atividades que possam favorecer a formação de valores, hábitos e atitudes voltados à boa convivência entre as diferentes gerações (intergeracionalidade).

Diante desses resultados, podemos afirmar que predominaram atitudes mais positivas do que negativas em ambos os grupos. Pode-se perceber que ainda não existe relação entre as variáveis 
“idade" e "atitude", uma vez que a opinião manifestada pelos idosos e pelos jovens foi semelhante. Ainda que tenham sido encontradas respostas mais positivas entre idosos e jovens, contraditoriamente, ao confrontá-las com as entrevistas, percebeu-se que os entrevistados responderam à questões similares às apresentadas na Escala Neri de forma mais negativa. Infere-se que seja devido à existência de preconceito implícito em relação ao idoso e a velhice que foram desvelados por meio das entrevistas.

Tais resultados reafirmam a ideia de que não existe uma resposta única no que tange ao envelhecimento, pois é um processo complexo e heterogêneo compreendendo relações biopsicossociais e culturais, como ficou demonstrado pelas visões plurais e multidimensionais dos sujeitos da pesquisa. Percebemos também que o envelhecimento saudável depende de investimentos sociais contínuos dirigidos aos cidadãos em todas as fases da vida, e não somente de investimentos individuais.

Outra constatação importante é a inexistência de projetos voltados aos idosos, e/ou a aproximação desses com outras gerações. Este tema não faz parte das propostas pedagógicas (PP), uma vez que por meio da análise desses documentos não se encontrou nenhuma referência direta ao assunto. Descobrimos, por meio das entrevistas com os alunos, a existência de ações isoladas que ocorrem por iniciativa de alguns professores e orientadores educacionais. Reconhecemos o valor das iniciativas, mas entendemos que elas não satisfazem as necessidades educativas de formação dos jovens, considerando a complexidade e relevância do tema.

Percebemos a necessidade de realizar na escola um trabalho de base, ou seja, preventivo, para juntar-se a outras áreas do conhecimento, tais como a saúde, a psicologia, a assistência social, entre outras, com o desafio de aproximar gerações, visando à superação de possíveis preconceitos, possibilitando a troca de experiências e a melhoria da qualidade de vida de todos.

Considerando que a educação busca o desenvolvimento integral e harmônico da pessoa, entendemos que os conteúdos escolares se tornam significativos na medida em que se situam em um tempo e espaço concretos de transformações de valores essenciais para a convivência. Os princípios voltados ao diálogo, que propiciam a dignidade, não podem ter fronteiras, devem transpassar todos os conteúdos escolares. Esses são justamente os conteúdos transversais. Assim, para lograr êxito, entendemos que a educação gerontológica deva fazer parte do currículo escolar e poderá ser trabalhada transversalmente, como já são desenvolvidos os temas transversais que compõem os Parâmetros Curriculares Nacionais (PCNs). ${ }^{26}$

A educação gerontológica pode fazer a diferença para os jovens no entendimento e no relacionamento com os idosos em casa, na comunidade e na sociedade em geral, e contribuir ainda para que envelheçam melhor e com mais qualidade de vida. Uma vez que o objetivo deste trabalho foi conhecer opiniões e estereótipos relativos à velhice com vistas a superar preconceitos e aproximar gerações, pode haver diferentes possibilidades contrutivas de trocas intergeracionais, em que idosos e jovens colaborem uns com os outros, como demostraram alguns estrevistados.

Alguns resultados encontrados nesta pesquisa coincidem com os estudados internacionais e nacionais. Destacamos as pesquisas de Neri, ${ }^{1}$ Souza, ${ }^{22}$ Andrade, ${ }^{18}$ e Novaes. ${ }^{23}$ Essas autoras pesquisaram a relação intergeracional em diferentes contextos e abordagens, constatando que os contatos intergeracionais foram satisfatórios e essenciais para evitar as imagens estereotipadas "do idoso fraco e doente que estão na base do conceito discriminatório da velhice (ageism)"..22

Reconhecendo a complexidade e a dimensão do assunto, percebemos a necessidade de se trabalhar a educação gerontológica e a relação intergeracional em outros espaços educativos, além da escola, tais como os centros de saúde, os clubes, as associações, os parques comunitários, enfim, onde houver espaço para a relação intergeracional. Acreditamos que as atividades que visem à promoção de encontros entre diferentes gerações 
trarão benefícios para todos os envolvidos, traduzidos em compreensão, respeito mútuo, afeto e mais qualidade de vida.

Portanto, é importante lembrar as recomendações da Organização Mundial da Saúde, ${ }^{19}$ que tratam da relevância da relação entre as gerações para a promoção da saúde e da

\section{REFERÊNCIAS}

1. Neri AL. Envelhecer num país de jovens: significado de velho e velhice Segundo brasileiros não idosos. Campinas: Editora da Unicamp; 1991.p.155

2. Cachioni M. Formação pofissional, motivos e crenças relativas à velhice e ao desenvolvimento pessoal entre professores de universidades da terceira idade. Campinas.tese [Doutorado em Gerontologia] - Unicamp; 2002.

3. Camarano A. Envelhecimento da população brasileira: uma contribuição demográfica. In Freitas EV, et al. Tratado de Geriatria e Gerontologia. Rio de Janeiro: Guanabara Koogan 2006; p. 88-104.

4. Faleiros V, Rebouças M. Gestão social por sujeito/idade na velhice. In: Faleiros V, Loureiro A .Desafios do envelhecimento: vez, sentido e voz. Brasília: Universa; 2006. p.111-32.

5. Todaro MÁ. Vovô vai à escola. Campinas: Papirus; 2009. p.112.

6. Instituto Brasileiro de Geografia e Estatística (IBGE). Síntese de indicadores sociais 2007. Disponível em URL: http://www.ibge.gov.br/

7. Brasil. Lei n. 8.842 , de 4 Janeiro de 1994.Política Nacional do Idoso. Diário Oficial da união 3 out 2003; 1(1). Disponível em URL: < http:// http:// www.planalto.gov.br/ccivil_03/leis/ 18842.htm >

8. Brasil. Lei n ${ }^{\circ} 10.741$, de 1 outubro de 2003. Estatuto do Idoso .Diário Oficial da União 3 out 2003; 1(1). Disponível em URL: < http:// www.planalto.gov.br/ccivil_03/leis/2003/ 110.741.htm >

9. Delors J. Educação: um tesouro a descobrir. São Paulo: Cortez e Unesco; 1999.

10. Lüdke M, André MA. Pesquisa em Educação: abordagens qualitativas. São Paulo: EPU; 1986. qualidade de vida, uma vez que o envelhecimento ocorre dentro de um contexto que envolve outras pessoas - amigos, colegas de trabalho, vizinhos e membros da família. A qualidade de vida que as pessoas terão quando avós depende não só dos riscos e oportunidades que experimentam durante a vida, mas também da maneira como as gerações posteriores ofereceram ajuda e apoio relacional.

11. Neri AL. Atitudes em relação à velhice: questões científicas e políticas. In Freitas EV ,et al . Tratado de Geriatria e Gerontologia. Rio de Janeiro: Guanabara Koogan; 2002. p. 972-980.

12. Levy BR. Eradication of geism Requires Addressing the Enemy Within. The Gerontologist 2001; 41 (5): 578-579.

13. Serviço Social do Comércio de São Paulo (SescSP) e Fundação Perseu Abramo. Pesquisa Idosos no Brasil: vivências, desafios e expectativas na $3^{\text {a }}$ idade.2010. Disponível em URL: < http:// www.fpa.org.br/area/pesquisaidosos $>$

14. Ferrigno JC. Co-educação entre Gerações: do conflito as desenvolvimento da solidariedade. In: Netto MP. Tratado de Geriatria e Gerontologia. 2 ed. São Paulo: Atheneu; 2007. p. 233-41.

15. Neri AL. Atitudes e preconceitos em relação à velhice. In Neri AL. Idosos no Brasil: vivências desafios e expectativas na terceira idade. São Paulo: SESC/ Perseu Abramo; 2007. p. 32- 46.

16. Andrade FJ. Uma experiência de solidariedade entre gerações: constructos para a formação pessoal e social de alunos de uma escola secundária. Lisboa: Ministério da Educação; 2002.p.405

17. Organização Mundial de Saúde (Brasil). Envelhecimento ativo: um projeto de Política de Saúde. 2005. Disponível em URL: < http:// bvsms.saude.gov.br/bvs/publicacoes/ envelhecimento_ativo.pdf $>$..

18. Erikson E. O ciclo de vida completo. Porto Alegre: Artes Médicas; 1998. p.111

19. Sommerhalder C, Nogueira E. As relações entre gerações. In : Neria FS . E por falar em boa velhice. Campinas: Papirus; 2000. p. 88-104.

20. Souza E. Remininiscências Integrando Gerações: a arte de compartilhar memórias. Petrópolis: Vozes; 1999. p.17-85. 
21. Novaes M . As gerações e suas lições de vida: aprender em tempo do viver. Rio de Janeiro : PUC; 2005. p.144.

22. Alves VP. A religião e os idosos. In: Faleiros V, Loureiro A . Desafios do Envelhecimento: vez, sentido e voz. Brasília: Universa; 2006. p. 45- 55.

23. Motta A. Sociabilidade possível: idosos e tempo geracional. In Peixoto, CE. Família e envelhecimento. In: Freitas EV, et al. Tratado de Geriatria e Gerontologia. Rio de Janeiro: Guanabara Koogan; 2006. p. 77- 82.

24. Secretaria de Educação Fundamental (Brasil). Parâmetros Curriculares Nacionais (PCNs). Brasília: MEC/SEF;1997.

25. Baltes P, Smith J. Psicologia da sabedoria: origem e desenvolvimento. Campinas: Papirus; 1995.

Recebido: 02/8/2010

Revisado: 01/2/2011

Aprovado: 18/2/2011 